\title{
Seed softening patterns of forage legumes in a temperate/subtropical environment in Uruguay
}

\author{
Javier Do Canto ${ }^{1}$, Rafael Reyno ${ }^{1}$, Daniel Real ${ }^{*}$, and Clinton Revell ${ }^{2}$
}

\begin{abstract}
Few studies have been conducted in annual and perennial forage legumes to investigate the development of hardseededness and the subsequent pattern of seed softening in temperate and subtropical regions of South America. Experiments were conducted during 2007 and 2008 in central Uruguay to follow the pattern of seed softening in 35 annual and perennial forage legumes, including three native species of Uruguay and five commercial cultivars. Newly ripened seeds of each plant material were placed in mesh packets on the soil surface in mid-summer. Samples were recovered monthly for germination tests and the proportion of residual hard seeds determined. The native species Adesmia bicolor (Poir.) DC., Adesmia securigerifolia Herter, and Ornithopus micranthus (Benth.) Arechav., together with Ornithopus pinnatus (Mill.) Druce cv. INIA Molles behaved similarly. They showed high levels of initial hard seed from $78 \%$ in A. bicolor to $99 \%$ in A. securigerifolia and O. pinnatus cv. INIA Molles in 2007; displayed pulses of seed softening, particularly in autumn, and retained moderate levels of residual hard seed for the development of a soil seed bank ranging from $15 \%$ in A. bicolor to $49 \%$ in $O$. micranthus. These appear to be desirable characteristics for persistence of forage legumes in subtropical grasslands, both for annual and perennial species. Trifolium repens L. and Lotus corniculatus L. produced few hard seeds, only $2 \%$ and $13 \%$ respectively were hard after 1-mo in the field and were completely soft by July placing extra reliance on their vegetative propagation for persistence. Materials of $L$. arenarius Brot. showed pronounced late autumn softening, while materials of L. ornithopodioides L. showed extremely high levels of hardseededness (between 96\% and 100\%) and no softening during the evaluation period, apart from two materials that were completely soft seeded. Mediterranean forage legumes should be properly evaluated in temperate and subtropical regions as their seed softening behavior is likely to be substantially modified in these summer moist environments.
\end{abstract}

Key words: Hard seeds, Adesmia, Ornithopus, Trifolium, Lotus.

\section{INTRODUCTION}

Seeds often possess dormancy mechanisms that prevent germination under conditions unsuitable for seedling establishment (Fenner, 1985) and in forage legumes the main form of dormancy is imposed by an impermeable seed coat, often referred to as hardseededness (Taylor, 2005). Hardseededness has two ecologically significant roles (Cocks et al., 1980) (i) it ensures survival in the absence of seed production through the development of soil seed banks (regulates germination between years), and (ii) it prevents germination of the seed bank outside the normal winter growing season such as in a 'Mediterranean' environment where summer rain can sometimes occur (regulates germination within years). Many studies have been conducted in Mediterranean environments in annual species such as Trifolium subterraneum L. and Medicago

${ }^{1}$ Instituto Nacional de Investigación Agropecuaria, INIA Tacuarembó, Ruta 5 km 386, Tacuarembó, Uruguay.

${ }^{2}$ Department of Agriculture and Food Western Australia, 3 Baron-Hay

Court, South Perth, WA 6151, Australia.

"Corresponding author (daniel.real@agric.wa.gov.au).

Received: 22 May 2012.

Accepted: 15 November 2012. spp. (Blumenthal and Ison, 1994; Piano et al., 1996; Taylor, 1996a; 1996b; 2005; Norman et al., 2006) to characterize their patterns of seed softening (the process whereby the seed coat becomes permeable).

Since only soft seeds may germinate after rainfall events, the timing of rainfall in relation to the pattern of seed softening within years will have an important bearing on legume persistence. A number of Mediterranean annual legume species have been shown to have an autumn pattern of seed softening explained by a conceptual two-stage model of seed softening (Taylor, 2005). The first or preconditioning stage takes place with time at a rate that increases with increasing temperature. Diurnal fluctuations in temperature within a particular range, which may be species- or even cultivar-specific, are necessary for the second (and final) stage of softening. If softening predominantly occurs in summer, seeds can germinate on out of season rainfall and subsequently die without follow up rainfall (often referred to as false breaks of season). However, if softening is delayed until autumn, germination will occur when the probability of follow up rains is much greater (Smith et al., 1996). Such a pattern has been found in Medicago polymorpha $\mathrm{L}$. (Taylor, 1996b) and in some cultivars of T. subterraneum 
(Norman et al., 2006). There is general agreement that seed softening patterns should be considered in forage legume breeding programs, particularly for environments where substantial losses of seed may occur due to false breaks of season (Piano et al., 1996; Smith et al., 1996; Taylor, 1996a; 1996b; Zeng et al., 2005a; Norman et al., 2006).

Little is known about the patterns of seed softening in temperate and subtropical regions of South America for either the native annual and perennial forage legumes or for the most widespread introduced Mediterranean annual and temperate perennial legumes (notably Trifolium repens L. and Lotus corniculatus L.). The aim of this study was to determine the pattern of seed softening of native and exotic forage legumes developed by the forage breeding program of the National Institute of Agricultural Research (INIA) at Tacuarembó, Uruguay. We hypothesize that the softening pattern of native species will be the most ecologically adapted pattern and that for exotic Mediterranean legumes to be successful in the temperate and subtropical environments, they will need to have a similar pattern of seed softening.

\section{MATERIALS AND METHODS}

\section{Plant material}

The experiments were conducted at Glencoe Research Field Station of INIA Uruguay at Paysandú (32 01 ' S, $57^{\circ} 09^{\prime} \mathrm{W}$ ) in 2007 and 2008 with a total of eight species of forage legumes represented by 35 materials: experimental lines (line), cultivars (cv.) or accessions (acc.) (Table 1). The species involved were two Uruguayan native annual (Adesmia securigerifolia Herter and Ornithopus micranthus Benth. Arechav.) and one perennial legume (Adesmia bicolor Poir. DC.) and, three Mediterranean annual (Ornithopus pinnatus Mill. Druce, Lotus ornithopodioides L., and Lotus arenarius Brot.) and two perennial legumes (T. repens and L. corniculatus). Newly ripened seeds from all plant materials were hand harvested from plants growing in pots between 10 December and 30 December of 2006 and 2007, in the same location as the seed softening studies. Seeds were removed from the pods by hand to avoid any damage/scratching of the seed coats and kept on a bench top under ambient conditions (20-25 ${ }^{\circ} \mathrm{C}$ and $\left.50-70 \% \mathrm{RH}\right)$ in a laboratory at INIA Tacuarembó

Table 1. Origin, growth cycle, and year of evaluation of all plant materials used in the evaluations.

\begin{tabular}{|c|c|c|c|c|c|}
\hline Species - material & Species origin & $\begin{array}{l}\text { Annual or } \\
\text { perennial }\end{array}$ & $\begin{array}{l}\text { Peak of } \\
\text { flowering }\end{array}$ & $\begin{array}{c}\text { Evaluated in } \\
2007\end{array}$ & $\begin{array}{c}\text { Evaluated in } \\
2008\end{array}$ \\
\hline Adesmia bicolor line G5 & Uruguay & $\mathrm{P}$ & Mid Nov & $\checkmark$ & $\checkmark$ \\
\hline A. securigerifolia acc. 7303 & Uruguay & A & Early Oct & $\checkmark$ & $\checkmark$ \\
\hline Ornithopus micranthus acc. 6200 & Uruguay & A & Early Oct & $\checkmark$ & $\checkmark$ \\
\hline O. pinnatus cv. INIA Molles ${ }^{1}$ & Mediterranean & A & Late Oct & $\checkmark$ & $\checkmark$ \\
\hline O. pinnatus cv. Jebala ${ }^{2}$ & Mediterranean & A & Mid Oct & & $\checkmark$ \\
\hline \multicolumn{6}{|l|}{ Lotus ornithopodioides } \\
\hline 6004 & Mediterranean & A & Early Nov & $\checkmark$ & \\
\hline 6005 & Mediterranean & A & Early Nov & $\checkmark$ & \\
\hline 6006 & Mediterranean & A & Early Nov & $\checkmark$ & \\
\hline cv. Junak ${ }^{3}$ & Mediterranean & A & Early Nov & $\checkmark$ & \\
\hline 6008 & Mediterranean & A & Mid Oct & $\checkmark$ & \\
\hline 6012 & Mediterranean & A & Mid Oct & $\checkmark$ & \\
\hline 6013 & Mediterranean & A & Mid Oct & $\checkmark$ & \\
\hline 6015 & Mediterranean & A & Oct & $\checkmark$ & \\
\hline 6018 & Mediterranean & A & Mid Oct & $\checkmark$ & \\
\hline 6020 & Mediterranean & A & Early Nov & $\checkmark$ & \\
\hline 6022 & Mediterranean & A & Oct & $\checkmark$ & \\
\hline \multicolumn{6}{|l|}{ L. arenarius } \\
\hline 6070 & Mediterranean & A & Early Oct & $\checkmark$ & \\
\hline 6073 & Mediterranean & A & Early Oct & $\checkmark$ & \\
\hline 6083 & Mediterranean & A & Mid Oct & $\checkmark$ & \\
\hline 6086 & Mediterranean & A & Early Oct & $\checkmark$ & \\
\hline 6087 & Mediterranean & A & Mid Oct & $\checkmark$ & \\
\hline 6090 & Mediterranean & A & Mid Oct & $\checkmark$ & \\
\hline 6092 & Mediterranean & A & Late Oct & $\checkmark$ & \\
\hline 6094 & Mediterranean & A & Late Oct & $\checkmark$ & \\
\hline 6097 & Mediterranean & A & Mid Oct & $\checkmark$ & \\
\hline 6098 & Mediterranean & A & Mid Oct & $\checkmark$ & \\
\hline 6102 & Mediterranean & A & Mid Oct & $\checkmark$ & \\
\hline 6105 & Mediterranean & A & Late Oct & $\checkmark$ & \\
\hline 6109 & Mediterranean & A & Mid Oct & $\checkmark$ & \\
\hline 6110 & Mediterranean & A & Oct & $\checkmark$ & \\
\hline 6111 & Mediterranean & A & Mid Oct & $\checkmark$ & \\
\hline 6113 & Mediterranean & A & Late Oct & $\checkmark$ & \\
\hline 6114 & Mediterranean & A & Oct & $\checkmark$ & \\
\hline Trifolium repens $\mathrm{cv}$. Zapican $^{1}$ & Mediterranean & $\mathrm{P}$ & Oct & & $\checkmark$ \\
\hline L. corniculatus cv. INIA Draco ${ }^{1}$ & Mediterranean & $\mathrm{P}$ & Dec-Jan & & $\checkmark$ \\
\hline
\end{tabular}

${ }^{1}$ Cultivar developed in Uruguay; ${ }^{2}$ cultivar developed in Australia; ${ }^{3}$ cultivar developed in Czech Republic. 
following harvest to the start of the experiment in February of each year.

\section{Field evaluation}

Fifty seeds from each plant material were placed in stainless steel mesh cells of $5 \mathrm{~cm} \times 5 \mathrm{~cm}$ each. On 9 February 2007 and 15 February 2008, in a patch of bare soil where native vegetation was removed, seeds in the mesh were placed on the soil surface, simulating the conditions for mature seeds after they have fallen from the plant. The treatments consisted of different periods of exposure to the environment, which was determined by the time when seeds were recovered from the soil surface. Seed lots were recovered at $30 \mathrm{~d}$ intervals and the number of germinated and non germinated seeds was counted. The 2007 and 2008 experiments were evaluated until July 9 and August 15 respectively. The 2007 experiment could not continue beyond July due to seed losses from the mesh.

\section{Laboratory phase}

Prior to the commencement of the 2007 experiment, a germination test was conducted on duplicate seed lots to determine the initial proportion of hard seeds of each plant material. An initial test was not conducted in the 2008 experiment. For both experiments, a germination test was conducted on the non-germinated seeds recovered from the soil surface at each recovery date. Seeds were placed in Petri dishes laid with wet filter paper and maintained in a growth chamber for $14 \mathrm{~d}$ at $20^{\circ} \mathrm{C}$ in presence of artificial light. Seeds that did not imbibe during the germination test were considered hard.

\section{Climate}

Uruguay is situated in a subtropical temperate region with no defined dry or wet seasons. The annual rainfall average for this location is $1293 \mathrm{~mm}$ and the monthly average is $108 \mathrm{~mm}$, which can be highly variable between years. For January, April and July, mean air temperatures are 25.2, 18.7 , and $11.9^{\circ} \mathrm{C}$, maximum averages are $32,24.1$, and $17^{\circ} \mathrm{C}$, while minimum averages are $18.4,13.4$ and $6.9^{\circ} \mathrm{C}$ (Castaño et al., 2011).

\section{Data analysis}

The experimental design was a randomized complete block design with two replicates in 2007 experiment and four replicates in 2008. ANOVA was used to test the effect of plant material between and within months using the SAS 9.2 statistical package and by Least Square Means when data was unbalanced.

\section{RESULTS}

\section{Weather conditions during the seed softening experiments}

The daily air temperature records generally showed higher diurnal temperature fluctuations during 2008 than in 2007 (Figure 1). Rainfall events were higher and more frequent during 2007, especially during the period from February to May (Figure 2).

\section{Seed softening - 2007}

Large differences in the initial content of hard seeds and in the pattern of softening were observed between and
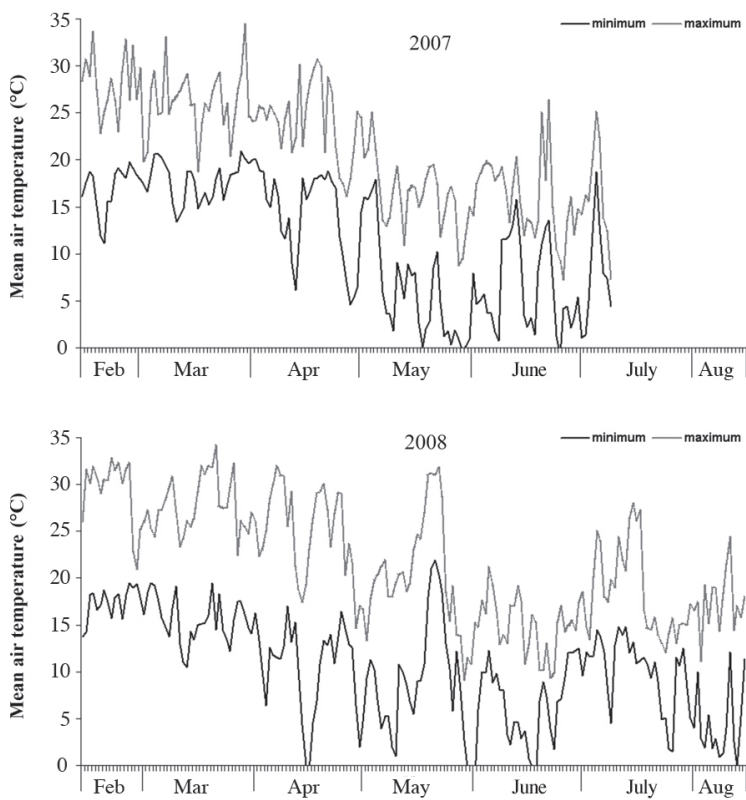

Figure 1. Daily maximum and minimum air temperatures during 2007 and 2008 .
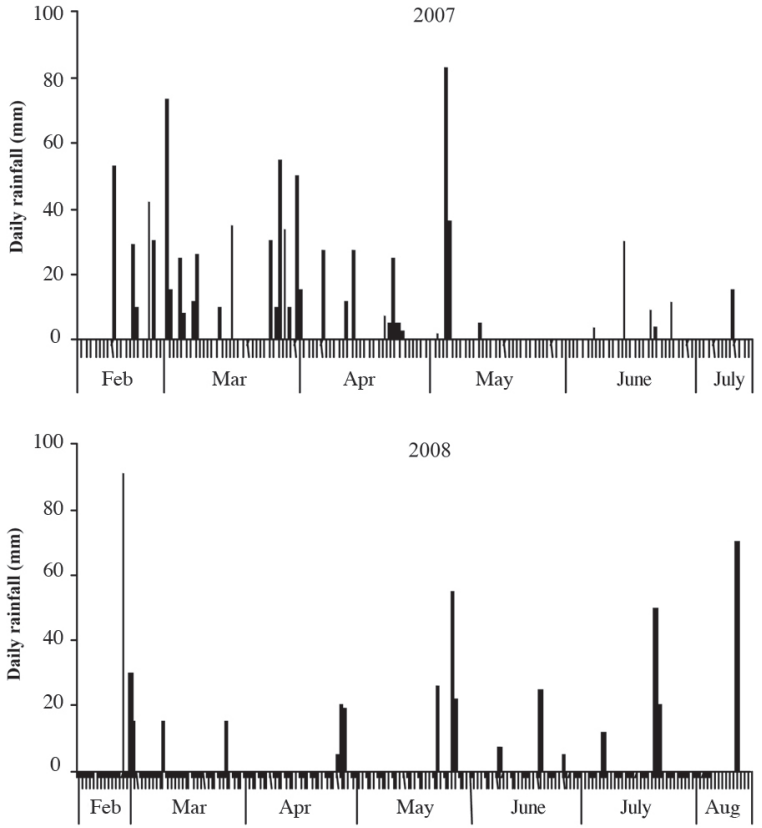

Figure 2. Distribution of daily rainfall during the 2007 and 2008 experiments. 
within species (Table 2). Most species had initial levels of hard seed greater than $95 \%$, but A. bicolor and several materials of $L$. arenarius had higher levels of hard seed after 1-mo in the field, indicating harvested seeds had not dehydrated sufficiently to express full hardseededness.

The greatest level of seed softening was found in $A$. bicolor (over $95 \%$ of hard seeds softened by July) followed by A. securigerifolia and O.pinnatus cv. INIAMolles (Table 2). Softening in A. bicolor and A. securigerifolia occurred in regular pulses over the autumn and winter, whereas in $O$. pinnatus it was concentrated in May and June. $L$. ornithopodioides showed very contrasting hardseed levels within species, with most materials achieving nearly $100 \%$ initial hardseededness, but two materials including cv. Junak were fully soft at maturity (i.e. never became hard) and all of them remained unchanged over the autumn and winter. Ornithopus micranthus showed a low to moderate level of softening, which occurred gradually over the autumn. Materials of L. arenarius showed variable levels of softening from over $80 \%$ (accession 6073) to less than $10 \%$ (accession 6113).

Table 2. Pattern of seed softening over the summer and autumn in 2007 (Experiment 1).

\begin{tabular}{|c|c|c|c|c|c|c|c|}
\hline \multirow{2}{*}{ Species-material } & & \multicolumn{6}{|c|}{ Hard seed $(\%)$} \\
\hline & & Initial & March & April & May & June & July \\
\hline Adesmia bicolor line G5 & $* * *$ & $78 b$ & $91 \mathrm{a}$ & $37 \mathrm{c}$ & $37 \mathrm{c}$ & $33 c$ & $3 d$ \\
\hline A. securigerifolia acc. 7303 & $* *$ & $99 \mathrm{a}$ & $74 \mathrm{~b}$ & $74 \mathrm{~b}$ & $52 b$ & $52 \mathrm{~b}$ & $26 \mathrm{c}$ \\
\hline Ornithopus micranthus acc. 6200 & $* * *$ & $97 \mathrm{a}$ & $98 \mathrm{a}$ & $92 \mathrm{ab}$ & $85 b$ & $69 \mathrm{c}$ & $73 c$ \\
\hline O. pinnatus cv. INIA Molles & $*$ & $99 \mathrm{a}$ & $81 \mathrm{ab}$ & $87 \mathrm{ab}$ & $47 \mathrm{bc}$ & $28 \mathrm{c}$ & $26 \mathrm{c}$ \\
\hline \multicolumn{8}{|l|}{ Lotus ornithopodioides } \\
\hline 6004 & ns & 100 & 99 & 96 & 97 & 91 & 84 \\
\hline 6005 & ns & 100 & 97 & 93 & 94 & 92 & 59 \\
\hline 6006 & ns & 0 & 2 & 4 & 0 & 1 & 1 \\
\hline cv. Junak & ns & 0 & 1 & 1 & 0 & 0 & 1 \\
\hline 6008 & ns & 100 & 96 & 99 & 93 & 88 & 88 \\
\hline 6012 & ns & 100 & 94 & 94 & 87 & 88 & 93 \\
\hline 6013 & ns & 100 & 98 & 94 & 95 & 98 & 97 \\
\hline 6015 & ns & 99 & 99 & 98 & 99 & 98 & 93 \\
\hline 6018 & ns & 100 & 94 & 96 & 92 & 93 & 89 \\
\hline 6020 & ns & 96 & 96 & 97 & 97 & 96 & 84 \\
\hline 6022 & ns & 98 & 100 & 92 & 91 & 92 & 94 \\
\hline \multicolumn{8}{|l|}{ L. arenarius } \\
\hline 6070 & ns & 81 & 96 & 72 & 73 & 76 & 77 \\
\hline 6073 & $*$ & $98 \mathrm{a}$ & $93 a$ & $91 \mathrm{a}$ & $89 a$ & $84 a$ & $26 b$ \\
\hline 6083 & $*$ & $64 a$ & $73 a$ & $70 \mathrm{a}$ & $59 a$ & $65 a$ & $17 b$ \\
\hline 6086 & ns & 66 & 97 & 90 & 87 & 87 & 81 \\
\hline 6087 & $*$ & $65 \mathrm{~b}$ & $93 a$ & $91 \mathrm{a}$ & $88 \mathrm{a}$ & $74 a b$ & $60 \mathrm{~b}$ \\
\hline 6090 & ns & 74 & 75 & 71 & 72 & 71 & 55 \\
\hline 6092 & ns & 75 & 88 & 77 & 77 & 72 & 63 \\
\hline 6094 & ns & 82 & 92 & 89 & 92 & 81 & 41 \\
\hline 6097 & $* * *$ & $22 \mathrm{c}$ & $89 a$ & $85 \mathrm{ab}$ & $84 a b$ & $78 b$ & $75 b$ \\
\hline 6098 & $*$ & $52 \mathrm{c}$ & $93 a$ & $91 \mathrm{ab}$ & $85 \mathrm{ab}$ & $71 \mathrm{bc}$ & $74 \mathrm{ab}$ \\
\hline 6102 & ns & 66 & 92 & 81 & 79 & 69 & 64 \\
\hline 6105 & ns & 76 & 82 & 84 & 85 & 86 & 65 \\
\hline 6109 & ns & 78 & 94 & 89 & 81 & 82 & 46 \\
\hline 6110 & ns & 83 & 92 & 89 & 88 & 89 & 85 \\
\hline 6111 & ns & 77 & 97 & 92 & 92 & 95 & 65 \\
\hline 6113 & ns & 83 & 97 & 87 & 90 & 90 & 89 \\
\hline 6114 & ns & 62 & 97 & 91 & 92 & 90 & 83 \\
\hline Significance & & & $* * *$ & $* * *$ & $* * *$ & $* * *$ & $* * *$ \\
\hline $\operatorname{LSD}(\alpha=0.05)$ & & & 12.4 & 15.9 & 15.6 & 15.1 & 45.7 \\
\hline
\end{tabular}

Values followed by the same letter in the same line do not differ significantly.

\section{Seed softening - 2008}

By March, only O. micranthus attained close to $100 \%$ initial hard seed followed by the $O$. pinnatus cultivars, but softening was greatest for O. micranthus (Table 3). Most softening in Ornithopus spp. occurred in April, but the percentage of softening was smaller for $O$. pinnatus cv. Jebala. In A. securigerifolia softening also occurred in April. Trifolium repens produced virtually no hard seeds and L. corniculatus had a low level of hard seeds that completely softened by June/July. Adesmia bicolor softened predominantly in May.

\section{Softening in species common to both years}

There were only four species represented by one plant material common to both 2007 and 2008 experiments (Table 1). The year of the experiment, month of seed test, species, and the interaction of year $\times$ species effects were all significant $(\mathrm{P}<0.001 ; \mathrm{P}<0.001 ; \mathrm{P}<0.01$, and $\mathrm{P}<$ 0.001 respectively), except for July, when the year effect was not significant $(\mathrm{P}=0.51)$. At a species level, the effects of month, year and the interaction of month $\times$ year were significant for the two native annuals A. securigerifolia $(\mathrm{P}$ $<0.001 ; \mathrm{P}<0.001$, and $\mathrm{P}=0.032)$ and $O$. micranthus $(\mathrm{P}$ $<0.001)$. For A. bicolor and O. pinnatus cv. INIA Molles, year effect was not significant $(\mathrm{P}=0.09$ and $\mathrm{P}=0.14)$, while month effect $(\mathrm{P}<0.001)$ and interaction month $\times$ year were significant $(\mathrm{P}=0.022$ for $O$. pinnatus and $\mathrm{P}<$ 0.001 for A. bicolor).

It is unclear whether A. bicolor and A. securigerifolia reached maximum hardseededness in 2008 so it is difficult to compare softening between years. For Ornithopus spp. where initial hard seed was high, softening occurred earlier in 2008 than in 2007. The level observed in $O$. micranthus in March of both years was similar, however after April the percentage of residual hard seed was lower in 2008 ( $\mathrm{P}<0.001)$. Softening for $O$. pinnatus cv. INIA Molles occurred in May in 2007 and April in 2008.

The combined pattern of seed softening for the four materials (least square means of both years) is presented in Table 4. By March residual hard seed for A. bicolor was $69 \%$ followed by significant softening in April

Table 3. Pattern of seed softening over the summer and autumn in 2008 (Experiment 2).

\begin{tabular}{|c|c|c|c|c|c|c|c|}
\hline \multirow[b]{2}{*}{ Species-material } & & \multicolumn{6}{|c|}{ Hard seed $(\%)$} \\
\hline & & Mar & Apr & May & Jun & Jul & Aug \\
\hline Adesmia bicolor line G5 & $* * *$ & $48 \mathrm{a}$ & $43 \mathrm{a}$ & $29 b$ & $28 b$ & $27 b$ & $22 b$ \\
\hline A. securigerifolia acc. 7303 & $* * *$ & $54 a$ & $32 b$ & $29 b$ & $29 b$ & $24 b$ & $24 b$ \\
\hline Ornithopus micranthus acc. 6200 & $* * *$ & $99 \mathrm{a}$ & $32 b$ & $24 b$ & $29 b$ & $25 \mathrm{~b}$ & $30 \mathrm{~b}$ \\
\hline O. pinnatus cv. INIA Molles & $* * *$ & $86 a$ & $40 \mathrm{~b}$ & $33 b$ & $31 b$ & $37 b$ & $38 \mathrm{~b}$ \\
\hline O. pinnatus cv. Jebala & $* *$ & $91 \mathrm{a}$ & $81 b$ & $75 \mathrm{bc}$ & $74 \mathrm{bc}$ & $71 \mathrm{c}$ & $73 \mathrm{bc}$ \\
\hline Trifolium repens cv. Zapicán & ns & 2 & 2 & 1 & 1 & 0 & 0 \\
\hline Lotus corniculatus cv. INIA Draco & $* * *$ & $13 \mathrm{a}$ & $14 \mathrm{a}$ & $15 \mathrm{a}$ & $9 \mathrm{a}$ & $1 b$ & $2 b$ \\
\hline Significance & & $* * *$ & $* * *$ & $* * *$ & $* * *$ & *** & $* * *$ \\
\hline $\operatorname{LSD}(\alpha=0.05)$ & & 5.1 & 13.4 & 11.3 & 11.3 & 12.3 & 9.0 \\
\hline
\end{tabular}

Values followed by the same letter in the same line do not differ significantly. 
Table 4. Least square means for percentage of hard seed in each plant material over time (mean of years).

\begin{tabular}{llllll}
\hline & \multicolumn{5}{c}{ Month } \\
\cline { 2 - 6 } Species-material & Mar & Apr & May & June & July \\
\hline Adesmia bicolor line G5 & $69 \mathrm{aC}$ & $40 \mathrm{bB}$ & $33 \mathrm{bB}$ & $30 \mathrm{bB}$ & $15 \mathrm{cB}$ \\
A. securigerifolia acc. 7303 & $64 \mathrm{aC}$ & $53 \mathrm{aA}$ & $41 \mathrm{bB}$ & $40 \mathrm{bAB}$ & $25 \mathrm{cB}$ \\
Ornithopus micranthus acc. 6200 & $98 \mathrm{aA}$ & $62 \mathrm{bA}$ & $55 \mathrm{bcA}$ & $49 \mathrm{cA}$ & $49 \mathrm{cA}$ \\
O. pinnatus cv. INIA Molles & $83 \mathrm{aB}$ & $63 \mathrm{bA}$ & $40 \mathrm{cB}$ & $29 \mathrm{cB}$ & $31 \mathrm{cB}$
\end{tabular}

Means in the same line differ $(\mathrm{P}<0.05)$ when lower case letter in the same line are different.

Means in the same column differ $(\mathrm{P}<0.05)$ when uppercase letter in the same column are different.

and another pulse in July. A. securigerifolia hard seed content in March was $64 \%$ and it was not significantly different from A. bicolor. O. micranthus had the highest hard seed content with $98 \%$ and was significantly different from the other species. O. pinnatus had $84 \%$ of hard seed, which was exceeded only by $O$. micranthus and was significantly different from the rest. For $A$. securigerifolia, softening occurred in May and July when hard seed decreased to $41 \%$ and $25 \%$ respectively. O. micranthus started softening in April and continued until June, while for $O$. pinnatus softening occurred between April and May. By July, 25\% of the seeds of $A$. securigerifolia still remained hard and this did not differ significantly from $A$. bicolor and $O$. pinnatus, while $O$. micranthus had the highest proportion of residual hard seeds.

\section{DISCUSSION}

In this temperate/subtropical environment, high levels of initial hard seed $(>90 \%)$ can be achieved in all Uruguayan native species (A. bicolor, A. securigerifolia, and $O$. micranthus) and other Mediterranean annual legumes; however, it is clear that the full expression of hard seed will vary from year to year. Much of the variation will be attributed to differences in seed moisture as seed dehydration will be slower in these environments given the higher relative humidity over summer. Quinlivan (1971) has described the importance of seed moisture in the development of hard seed and Taylor (2005) has further emphasized the need to ensure tests of initial hard seed are conducted on seeds below 5-7\% moisture. This may be appropriate for 'Mediterranean' climates with hot dry summers but may not be realistic in the field for temperate and subtropical environments. Rainfall or high humidity during the final stages of seed formation can reduce initial hard seed, presumably as expansion of the seed during rehydration can cause irreversible widespread rupturing of the seed coat (Taylor, 2005). Further studies of seed dehydration under temperate and subtropical conditions are required. It is unclear whether the low level of hardseededness in A. bicolor and $A$. securigerifolia in March 2008 was due to a low initial level of hardseededness or to rapid softening in the first month.
The April and May seed softening of the native species is consistent with autumn softening described in other forage legumes like M. polymorpha (Taylor, 1996b; 2005). This suggests autumn softening has evolved as an adaptive feature in this environment and given the high incidence of germinating rainfall events in summer (Figure 2), it reduces the risk of large seedling losses if there is no follow-up rainfall. Autumn softening also implies that relatively lower diurnal fluctuations in temperature are required for the second (final) stage of seed softening, but these temperatures are likely to be species-specific (Taylor, 2005). Diurnal fluctuations in the vicinity of $30 / 15^{\circ} \mathrm{C}$ have been shown to be effective in $M$. polymorpha (Taylor, 1996b) and $47 / 15^{\circ} \mathrm{C}$ in one cultivar of Ornithopus compressus L. (Revell and Taylor, 1998). The multiple pulses of softening in the native species (Table 4), most pronounced in 2008 and occurring as late as July may be a response to a particular set(s) of diurnal temperature fluctuations that occurred more frequently in that year (Figure 1). Further work is required to relate the final stage of seed softening to soil temperatures over these periods in these species. Considering the variability in the timing and amount of rainfall events between years (Figure 2), gradual and continual seed softening over the autumn into early winter could be an advantage for subtropical species to capitalize on more frequent germinating rainfall events. The earlier that annual pastures can successfully establish the more productive they will be (Loi and Nutt, 2010).

The low to moderate level of residual hard seed of the native species at the end of the first year softening process (generally greater than $25 \%$ ) will contribute to the development of a soil seed bank. Such a level is similar to residual hard seed levels after $1 \mathrm{yr}$ of softening in $T$. subterraneum (Norman et al., 2006) and is sufficient to confer year to year persistence in permanent pastures. It may not be sufficient where there are multiple years with no seed production, such as consecutive winter grain crops or years of drought. As the age of the pastures increase, different generations of seeds are integrated into the soil seed bank. The year to year pattern of seed softening in these native species is unknown and the evidence suggests that it cannot be inferred by what happens in the first growing season. Norman et al. (2006) found no relationship between within-year and between-year hardseededness in T. subterraneum, and a faster rate of softening occurred in the second year in some annual clovers (Norman et al., 2002a). Smith et al. (1996) found differences in the timing of rapid softening between years in subterranean clover, M. polymorpha and Trifolium glomeratum $\mathrm{L}$. and it was suggested that seeds of a given genotype which soften in the first year may do so in response to a different stimuli to those that soften in subsequent years. Moreover, in the case of $O$. pinnatus cultivars, pods may insulate the seeds from extreme temperatures, resulting in a slower rate of seed softening (Bolland, 1985). More rapid softening 
can be expected in the second year. In other situations, a proportion of seeds can be buried, protecting seeds from extreme temperatures causing a slower rate of softening as occurs with M. polymorpha, Trifolium lappaceum L., T. glanduliferum Boiss. and T. subterraneum (Zeng et al., 2005b), or can accelerate softening, as in the case of $T$. clypeatum L., T. spumosum L. (Zeng et al., 2005b) and $O$. compressus (Revell et al., 1998; Taylor and Revell, 2002).

Of the annual exotic species evaluated the $O$. pinnatus cv. INIA Molles is likely to persist well in this environment as it has a very similar seed softening profile to the native species, supporting our overall hypothesis. Ornithopus pinnatus cv. Jebala may be more problematic, as although there was some evidence of autumn softening, the level of residual hard seed was much higher.

While some autumn softening was evident in one material of L. arenarius, it continued into early winter, and in many materials was quite pronounced as late as July. Very little softening occurred in most materials of L. ornithopodioides in early winter, suggesting some particularly low diurnal temperature fluctuations may be required. While residual hard seeds in these species were generally much higher than for the native species, there was enough variation to suggest that selection for softer seeded materials might be possible. While late season softening may ensure germination when rainfall is adequate, it may be impacted by low temperatures. The germination process in L. ornithopodioides is much slower when the temperature is lower than $10^{\circ} \mathrm{C}$ (Cristaudo et al., 2007). The two completely soft seeded lines of L. ornithopodioides (including cv. Junak) are unlikely to have long term persistence in the field but may provide useful options for short pasture phases as described for $O$. sativus Brot. cv. Cadiz in Australia (Revell, 2001). In these situations lower seed processing costs resulting from the absence of a requirement for seed scarification for maximum germination is an advantage.

Low levels of seed softening have been reported for $O$. compressus (Revell et al., 1998; Taylor and Revell, 2002), Trifolium hirtum All. (Fairbrother, 1997), Medicago orbicularis (L.) Bartal. and Medicago rotata Boiss. (Russi et al., 1992). This trait may produce a persistent seed bank but in some years seedling regeneration may be poor because of the low availability of soft (germinable) seeds. Variation in the softening pattern within species has been reported in M.polymorpha (Taylor, 1996b), O. compressus (Revell et al., 1998), T. subterraneum (Smith et al., 1996; Norman et al., 2006), and in other annual clovers (Norman et al., 2002b). This genetic diversity gives the advantage to persist in a wider range of environmental conditions and also gives the possibility of selection for hard seed content and rate of softening. Some evidence suggests that different seed softening strategies can co-exist in the same environment. Norman et al. (2002a) found that annual clover species from the same collection site had different patterns of seed softening. The use of compatible species and cultivar mixtures will no doubt improve the prospect for legume persistence, particularly for annual pastures.

The perennials $T$. repens and $L$. corniculatus are the most widespread forage legumes in Uruguay. The very low levels of hard seed in these species is in stark contrast to the annual species but is typical of the perennial growth form where persistence is vegetative rather than through a requirement to develop a large soil seed bank. Different results were obtained by Olmos et al. (2004), they found up to $80 \%$ hard seed in hand harvested inflorescences of some white clover populations. However, soil seed bank measures indicated that the number of seeds in the soil decreased quickly after 1 yr. The late seed softening that did occur in L. corniculatus is consistent with the results of Olmos (2001) in Uruguay, where the maximum recruitment of new seedlings occurred during July and August. Low temperature requirements for breaking seed coat imposed dormancy were also reported in Lotus tenuis Waldst. \& Kit. ex Willd. (Clua and Gimenez, 2003), in which $100 \mathrm{~d}$ at $5^{\circ} \mathrm{C}$ enhanced germination. The moderate level of hardseededness in the native perennial legume $A$. bicolor suggests that in natural ecosystems, persistence through a combination of vegetative propagation and development of a long term seed bank will be more resilient than relying on vegetative characteristics alone.

The more rapid softening in 2008 of the four species evaluated in both years may be attributed to the higher summer temperatures (Figure 1) and greater preconditioning (the first stage of seed softening) over this period. Although environmental conditions during seed development may have affected the initial hard seed content and softening behavior (Taylor, 1996a; Norman et al., 2006), temperature requirements for within year (short term) softening are little influenced by the seed growing environments and a similar pattern of softening may be expected from year to year (Taylor, 1996a).

\section{CONCLUSIONS}

Differences in the hardseededness of newly ripened seeds and pattern of seed softening are reported for a range of annual and perennial forage legumes (both native and exotic) in a temperate/subtropical environment in Uruguay. The native species ( $A$. bicolor, A. securigerifolia, and $O$. micranthus) were found to have high levels of initial hard seed, displayed pulses of seed softening, particularly in autumn, and retained moderate levels of residual hard seed for the development of a soil seed bank. These characteristics are likely to be important for the persistence of forage legumes where temperate/ subtropical conditions are experienced over summer. The exotic perennial species commonly used in Uruguay had little or no seed dormancy and their seed bank can disappear within a growing season. Their persistence depends on vegetative propagation from year to year or 
frequent resowing. Mediterranean forage legumes should be properly evaluated in temperate and subtropical regions as their seed softening behavior is likely to be substantially modified in these summer moist environments. Autumn softening is an important characteristic and further work is required to relate the final stage of seed softening to specific soil temperatures over this period for each species.

\section{ACKNOWLEDGEMENTS}

The authors wish to acknowledge the technicians Ana Viana, Ruben Merola, and Mauro Zarza for their assistance in the field and laboratory phases. Funding was provided by the Instituto Nacional de Investigación Agropecuaria (INIA), Uruguay.

\section{LITERATURE CITED}

Blumenthal, M.J., and R.L. Ison. 1994. Plant population dynamics in subterranean clover and murex medic swards. I. Size and composition of the sed bank. Australian Journal of Agricultural Research 45:913-928.

Bolland, M.D.A. 1985. Serradella (Ornithopus sp.): maturity range and hard seed studies of some strains of five species. Australian Journal of Experimental Agriculture 25:580-587.

Castaño, J.P., A. Gimenez, M. Ceroni, J. Furest, y R. Aunchayna. 2011. Caracterización agroclimática del Uruguay 1980-2009. 34 p. Instituto Nacional de Investigación Agropecuaria INIA, Montevideo, Uruguay.

Clua, A.A., and G.O. Gimenez. 2003. Environmental factors during seed development of narrow-leaved birdsfoot trefoil (Lotus tenuis) inlfuences subsequent dormancy and germination. Grass \& Forage Science 58:333-338.

Cocks, P.S., M.J. Mathison, and E.J. Crawford. 1980. From wild plants to pasture cultivars: annual medics and subterranean clover in southern Australia. p. 569-596. In Summerfield, R.J., and A.H. Bunting (eds.) Advances in legume science. Royal Botanic Gardens, Kew, Crown, London, UK.

Cristaudo, A., F. Gresta, G. Avola, and V. Miano. 2007. Germination capability of immature seeds of Lotus ornithopodioides L. and Scorpiurus subvillosus L. Options Méditerranéennes 79:289-292.

Fairbrother, T.E. 1997. Softening and loss of subterranean clover hard seed under sod and bare ground environments. Crop Science 37:839-844.

Fenner, M. 1985. Seed ecology. 151 p. Chapman and Hall, London, UK.

Loi, A., and B.J. Nutt. 2010. Twin sowing and summer sowing: alternative techniques to introduce legumes into pastures p. 97100. In Porqueddu, C., and S. Rios (eds.) The contributions of grasslands to the conservation of Mediterranean biodiversity. Options Méditerranéenes, CIHEAM, Alicante, Spain.

Norman, H.C., P.S. Cocks, and N.W. Galwey. 2002a. Hardseededness in annual clovers: variation between populations from wet and dry environments. Australian Journal of Agricultural Research $53: 821-829$
Norman, H.C., N.W. Galwey, and P.S. Cocks. 2002b. Hardseededness in annual clovers: variation within populations and subsequent shifts due to environmental changes. Australian Journal of Agricultural Research 53:831-836.

Norman, H.C., F.P. Smith, P.G.H. Nichols, P. Si, and N.W. Galwey. 2006. Variation in seed softening patterns and impact of seed production environment on hardseededness in early-maturing genotypes of subterranean clover. Australian Journal of Agricultural Research 57:65-74.

Olmos, F. 2001. Mejoramiento de pasturas con Lotus en la región noreste. 298 p. INIA Tacuarembó, Montevideo, Uruguay.

Olmos, F., M. Sosa, D. Wilman, y R. Sackville-Hamilton. 2004. Dinámica poblacional de trébol blanco: banco de semillas en el suelo. p. 103-126. In Factores que afectan la persistencia y productividad de pasturas mejoradas con trébol blanco (Trifolium repens L.) INIA Tacuarembó, Montevideo, Uruguay.

Piano, E., L. Pecetti, and A.M. Carroni. 1996. Climatic adaptation in subterranean clover populations. Euphytica 92:39-44.

Quinlivan, B.J. 1971. Seed coat impermeability in legumes. Journal of the Australian Institute of Agricultural Science 37:283-295.

Revell, C.K. 2001. How much ryegrass control from short term pastures. p. 58-59. In The 2001 Australian Grains Field Research Manual. Grains Research \& Development Corporation (GRDC), Toowoomba, Australia.

Revell, C.K., and G.B. Taylor. 1998. Effect of temperature and light on seed softening in yellow serradella. p. 195-198. In Michalk, D.L., and J.E. Pratley (eds.) Proceedings of the $9^{\text {th }}$ Australian Agronomy Conference. 20-23 July 1998. Australian Society of Agronomy, Charles Sturt University, Wagga Wagga, New South Wales, Australia.

Revell, C.K., G.B. Taylor, and P.S. Cocks. 1998. Long-term softening of surface and buried hard seeds of yellow serradella grown in a range of environments. Australian Journal of Agricultural Research 49:673-686.

Russi, L., P.S. Cocks, and E.H. Roberts. 1992. Hard-seededness and seed bank dynamics of six pasture legumes. Seed Science Research 2:231-241.

Smith, F., P. Cocks, and M. Ewing. 1996. Short-term patterns of seed softening in Trifolium subterraneum, T. glomeratum and Medicago polymorpha. Australian Journal of Agricultural Research 47:775-785.

Taylor, G. 1996a. Effect of the environment in which seeds are grown and softened on the incidence of autumn seed softening in two species of annual medics. Australian Journal of Agricultural Research 47:141-159.

Taylor, G. 1996b. Incidence and measurement of autumn seed softening within Medicago polymorpha L. Australian Journal of Agricultural Research 47:575-586.

Taylor, G.B. 2005. Hardseededness in Mediterranean annual pasture legumes in Australia: A review. Australian Journal of Agricultural Research 56:645-661.

Taylor, G.B., and C.K. Revell. 2002. Seed softening, imbibition time, and seedling establishmentin yellow serradella. Australian Journal of Agricultural Research 53:1011-1018.

Zeng, L.W., P.S. Cocks, and S.G. Kailis. 2005a. Softening of impermeable seeds of six Mediterranean annual legumes on the soil surface and buried beneath the soil surface. Seed Science and Technology 33:551-561.

Zeng, L.W., P.S. Cocks, S.G. Kailis, and J. Kuo. 2005b. Structure of the seed coat and its relationship to seed softening in Mediterranean annual legumes. Seed Science and Technology 33:351-362. 